\title{
Colorectal cancer susceptibility associated with the hMLH1 V384D variant
}

\author{
TOMONORI OHSAWA ${ }^{1,4}$, TOMOKO SAHARA ${ }^{1,5}$, SHINO MURAMATSU ${ }^{1,5}$, YOJI NISHIMURA ${ }^{2}$, \\ TOSHIMASA YATHUOKA ${ }^{2}$, YOICHI TANAKA ${ }^{2}$, KENSEI YAMAGUCHI ${ }^{3}$, \\ HIDEYUKI ISHIDA $^{4}$ and KIWAMU AKAGI ${ }^{1}$
}

\begin{abstract}
Divisions of ${ }^{1}$ Molecular Diagnosis and Cancer Prevention, ${ }^{2}$ Gastroenterological Surgery, and ${ }^{3}$ Gastroenterology, Saitama Cancer Center, 818 Komuro Ina, Kitaadachigun, Saitama 362-0806; ${ }^{4}$ Department of Digestive Tract and General Surgery, Saitama Medical Center, Saitama Medical University, 1981 Kamoda, Kawagoe,

Saitama 362-0806; ${ }^{5}$ Genetic Counseling Program, Graduate School of Humanities and Sciences,

Ochanomizu University, 2-1-1 Ohtsuka, Bunkyo-ku, Tokyo 112-8610, Japan
\end{abstract}

Received April 7, 2009; Accepted July 16, 2009

DOI: $10.3892 / \mathrm{mmr} 00000187$

\begin{abstract}
Lynch syndrome is an autosomal dominant colorectal cancer susceptibility syndrome caused by a dysfunction of DNA mismatch repair genes, including $M L H 1, M S H 2$, MSH6 and PMS2. However, the interpretation of certain changes in the mismatch repair genes is perplexing, as these changes do not necessarily affect the function of the protein. The pathogenicity of the $h M L H 1 \quad 1151 \mathrm{~T} \rightarrow \mathrm{A}$ variant, which results in an amino-acid substitution of valine for aspartic acid at codon 384 (V384D), is also controversial. This study was undertaken to assess the clinicopathological features of colorectal cancer patients harboring the $h M L H 1$ V384D variant. Two independent Japanese cohorts, comprising 670 colorectal cancer patients and 332 cancer-free controls, respectively, were genotyped by polymerase chain reaction (PCR)-RFLP. The allele frequency of V384D was $0.75 \%$ in the control group and $3.1 \%$ in the colorectal cancer group $(\mathrm{p}<0.001)$. Thus, the V384D variant was associated with increased colorectal cancer susceptibility. However, only $5 \%$ of the colorectal cancer patients carrying the V384D variant had high microsatellite instability; most had microsatellite-stable cancer. Additionally, these patients had no clear familial history of Lynch syndrome-related tumors. The combined results indicate that $h M L H 1$ V384D allele frequency was 4.1-fold higher in the colorectal cancer group than in the control group. Thus, the hMLH1 V384D variant may contribute to the development of microsatellite-instable as well as -stable colorectal cancer.
\end{abstract}

Correspondence to: Dr Kiwamu Akagi, Division of Molecular Diagnosis and Cancer Prevention, Saitama Cancer Center, 818 Komuro Ina, Kitaadachigun, Saitama 362-0806, Japan

E-mail: akagi@cancer-c.pref.saitama.jp

Key words: colorectal cancer, microsatellite instability, $h M L H 1$, Lynch syndrome, variant, RFLP

\section{Introduction}

Lynch syndrome, also called hereditary non-polyposis colorectal cancer (HNPCC), is one of the most common hereditary cancer susceptibility disorders. It has an autosomal dominant mode of inheritance, and entails an increased risk of developing a variety of cancers, including colorectal, endometrial, stomach, ovarian, small-bowel, ureteral, renal pelvis and hepatobiliary cancer (1). The syndrome is caused by inactivating mutations of the DNA mismatch repair (MMR) genes $h M L H 1, h M S H 2$, hMSH6 and hPMS2; the most common mutations arise in hMSH2 and hMLH1 (2-6). Dysfunction of the DNA MMR system accelerates the accumulation of mutations and changes in the length of simple and repetitive sequences ubiquitously throughout the genome. Cancers with these alterations are recognized as microsatellite instability-high (MSI-H) in approximately $90 \%$ of Lynch syndrome-related colorectal cancers (CRCs). Therefore, microsatellite instability (MSI) analysis is a very useful method for identifying Lynch syndrome. However, approximately $10 \%$ of sporadic CRCs are also MSI-H (7-10), and most of them fail to express $h M L H 1$ protein as a result of the hypermethylation of the promoter of the $h M L H 1$ gene $(11,12)$. Therefore, the finding of high microsatellite instability is suggestive of Lynch syndrome, but not diagnostic.

On the other hand, the Amsterdam criteria for suspecting Lynch syndrome are based on a family history of at least three relatives with Lynch syndrome-associated cancer, one affected relative being a first-degree relative of the other two, two successive generations being affected, and at least one relative having been affected at under 50 years of age (13). Although these criteria are stringent, their sensitivity and specificity are too low. The less stringent Bethesda guidelines for suspecting Lynch syndrome have been proposed to help select patients for MSI testing (14). The final diagnosis of Lynch syndrome is based on the presence of a germ-line mutation in an MMR gene.

However, searching for mutations in the four MMR genes is difficult and laborious, and the interpretation of certain changes 
in the MMR genes is often perplexing, as they do not necessarily affect the function of the protein. As a result, phenotype-genotype segregation analysis, comparative analysis of amino acids in different species, crystal structure analysis, allele frequency analysis in the general population and functional analysis, among others, have been used in an attempt to assess the pathogenic significance of changes in the MMR genes (15-19). In the present study, we investigated the clinicopathological features of patients with the V384D variant of the $h M L H 1$ gene in a series of 670 cases of CRC.

\section{Materials and methods}

Samples and DNA extraction. Paired specimens of colorectal tumors and normal colorectal mucosa from 670 Japanese CRC patients and peripheral blood samples from a healthy control group of 332 Japanese cancer-free individuals were collected with the informed consent of the subjects. Patients who had received pre-operative radiotherapy or chemotherapy and patients with inflammatory bowel disease or a known history of familial adenomatous polyposis were excluded. This study was approved by the Ethics Committee of the Saitama Cancer Center. Fresh representative tissue samples from all tumor tissues and normal colorectal mucosa were immediately frozen at $-80^{\circ} \mathrm{C}$. Genomic DNA was extracted by the standard method (20). DNA was extracted from blood specimens using the QIAamp DNA Blood Maxi Kit (Quiagen, Valencia, CA, USA) according to the manufacturer's instructions.

Clinicopathological analysis. A clinical database was prepared, and pathological stage, tumor cell type and tumor size were independently determined by pathologists without any knowledge regarding microsatellite status or the presence of the $h M L H 1$ V384D variant. The $\chi^{2}$ or Fisher's exact test was used to assess any differences between the presence and absence of the V384D variant in patients with CRC. Statistical analyses were performed using the StatView 5.5 program. A p-value $<0.05$ was considered to be statistically significant.

Analysis of microsatellite instability. The microsatellite markers used in this study were BAT25, BAT26, D5S346, D2S123 and D17S250, recommended by the National Cancer Institute Workshop (21). MSI analysis was carried out using a fluorescence-based polymerase chain reaction (PCR) technique (8). The products were run on an ALF express DNA sequencer (Pharmacia Biotech, Uppsala, Sweden), and a subsequent analysis was performed using the Allele Links software program. Tumors were classified as MSI-H if more than one marker showed MSI, and as microsatellite instability-low (MSI-L) if only one marker showed MSI. Microsatellite-stable (MSS) tumors were characterized by the absence of microsatellite instability in all 5 markers. When an MSI marker was found to be positive, testing was repeated to confirm the results.

Detection of the V384D variant of $M$ MHH1. To detect the V384D variant of $h M L H 1$, exon 12 of the $h M L H 1$ gene was amplified by PCR using the primers 5'-ATCCACAACAAGTCTGAC CTCG-3' (sense) and 5'-AAGCATCTCCTCATCTTGCTGC-3' (antisense). Thermal cycling was initiated by denaturation at $95^{\circ} \mathrm{C}$ for $2 \mathrm{~min}$, followed by 35 three-step cycles at $94^{\circ} \mathrm{C}$ for

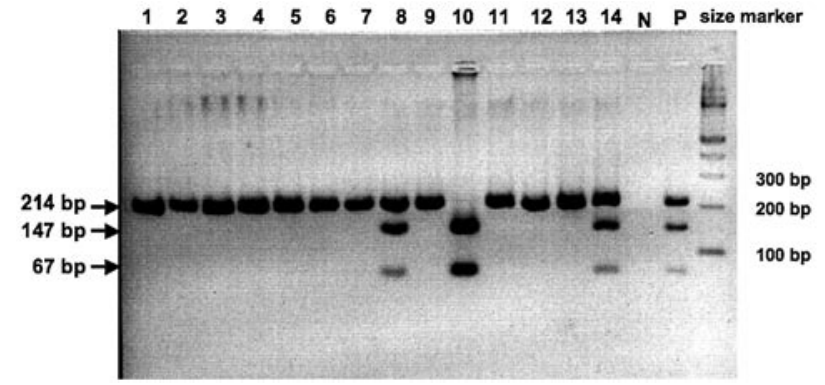

Figure 1. PCR-RFLP for the detection of the V384D variant. Exon 12 of the $h M L H 1$ gene was amplified by PCR. The 214-bp PCR products were treated with DpnII at $37^{\circ} \mathrm{C}$ for $1 \mathrm{~h}$ and electrophoresed through a $3 \%$ agarose gel. When the V384D variant was present, 67 and $147 \mathrm{bp}$ fragments were observed. Lane 10 shows the results for a V384D homozygote, and lanes 8 and 14 show the results for V384D heterozygotes.

$30 \mathrm{sec}, 60^{\circ} \mathrm{C}$ for $45 \mathrm{sec}$ and $72^{\circ} \mathrm{C}$ for $30 \mathrm{sec}$, and then by a final incubation for $5 \mathrm{~min}$ at $72^{\circ} \mathrm{C}$. The 214-base pair (bp) PCR products were treated with $\mathrm{DpnII}$ at $37^{\circ} \mathrm{C}$ for $1 \mathrm{~h}$ and electrophoresed through $3 \%$ agarose gel. When the V384D variant was present, $67 \mathrm{bp}$ and $147 \mathrm{bp}$ fragments were observed (Fig. 1).

\section{Results}

Characterization of the patients and tumors. The clinicopathological features of the CRC patients, including age at diagnosis, gender, tumor size and location, tumor stage and histology, are shown in Table I. Comparison with the large prospective registry data reviewed by the Japanese Society for Cancer of the Colon and Rectum, representative of the Japanese population (22), showed that almost all of the features were concordant (data not shown). This indicates that our samples were representative of the Japanese population (8).

Of the 670 CRC patients, $40(6.0 \%)$ had MSI-H cancers, $41(6.1 \%)$ had MSI-L cancers and $589(87.9 \%)$ had MSS cancers (Table I). Multiple CRC and extracolonic cancers were observed in 44 and 75 patients, respectively.

Frequency of the V384D variant in $h M L H 1$. The V384D variant was detected in $40(6.0 \%)$ of the $670 \mathrm{CRC}$ patients (39 of whom were heterozygous and 1 of whom was homozygous). The V384D variant was detected in $5(1.5 \%)$ of the 332 controls, all 5 of whom were heterozygous (Table II). Thus, the frequency of the V384D allele was 4.1-fold higher in the CRC group than in the control group $(\mathrm{p}<0.002)$. The clinicopathological characteristics of the V384D carriers and non-V384D carriers are shown in Table III.

The mean age at diagnosis was lower in the V384D carriers (61.1 years old) than in the non-V384D carriers (63.4 years old), but the difference was not statistically significant $(\mathrm{p}=0.08)$. Of the 40 V384D carriers, 2 (5.0\%) had MSI-H, 4 (10.8\%) had MSI-L and $34(81.1 \%)$ had MSS cancer. The frequency of MSIpositive (MSI-H and -L) cancers was higher among the V384D carriers than among the non-V384D carriers.

The site of the tumor and the histological findings in the V384D carriers and non-V384D carriers were similar; however, comparison of their Dukes' stages revealed a higher frequency of Dukes' B stage (40.0\%) and lower frequency of Dukes' D stage 
Table I. Clinical characteristics of the CRC patients.

\begin{tabular}{lrc}
\hline & No. $(\%)$ \\
\hline Gender & & \\
$\quad$ Male & 391 & $(58.4)$ \\
Female & 279 & $(41.6)$ \\
Age (mean \pm SD, years) & $63.1 \pm 14.3$ \\
Size of tumor (mean \pm SD, mm) & $46.2 \pm 25.8$ \\
Site of tumor & & \\
Cecum & 43 & $(6.4)$ \\
Ascending colon & 86 & $(12.8)$ \\
Transverse colon & 60 & $(9.0)$ \\
Descending colon & 24 & $(3.6)$ \\
Sigmoid colon & 176 & $(26.3)$ \\
Rectum & 281 & $(41.9)$ \\
Histological grade & & \\
Well differentiated & 79 & $(11.8)$ \\
Moderately differentiated & 548 & $(81.8)$ \\
Poorly differentiated & 43 & $(6.4)$ \\
Mucinous component & & \\
+ & 81 & $(12.1)$ \\
- & 589 & $(87.9)$ \\
Dukes' stage & & \\
A & 147 & $(21.9)$ \\
B & 197 & $(29.4)$ \\
C & 193 & $(28.8)$ \\
D & 133 & $(19.9)$ \\
Multiple CRC & 44 & $(6.6)$ \\
Extracolonic cancers & 75 & $(11.2)$ \\
Microsatellite instability & & \\
MSI-H & 40 & $(6.0)$ \\
MSI-L & 41 & $(6.1)$ \\
MSS & 589 & $(87.9)$ \\
& & \\
\hline
\end{tabular}

$(10.0 \%)$ in the V384D carriers. These tumor stage proportions are very similar to those of patients with MSI-H CRC $(8,23)$.

\section{Discussion}

Lynch syndrome is an autosomal dominant colorectal cancersusceptibility syndrome caused by the disfunction of the hMLH1, hMSH2, hMSH6 and hPMS2 MMR genes (2-6). Microsatellite instability is observed in most Lynch syndrome tumors. In the Japan population of this study, we found that the allele frequency of the $h M L H 11151 \mathrm{~T} \rightarrow \mathrm{A}$ variant, which results in the amino-acid substitution V384D, was 4.1-fold higher in the CRC group than in the control group $(\mathrm{p}<0.002)$. Thus, the MLH1 1151A variant was associated with CRC susceptibility. However, most of the CRCs that developed in the V384D carriers demonstrated MSS, and no clear familial history of CRC was observed in the patients, in contrast to typical Lynch syndrome.
Wang et al reported the results of a study on the $h M L H 1$ V384D variant among healthy Germans $(n=100)$, German CRC patients $(n=109)$, healthy Japanese $(n=80)$ and Chinese CRC patients $(n=26)$ (18). They did not detect the MLH1 1151A variant in healthy Germans or German patients with familial CRC or early-onset CRC, but did detect it in $2.5 \%$ of the healthy Japanese and $7.7 \%$ of the Chinese CRC patients. Thus, the frequency of the $h M L H 1$ V384D variant was 3-fold higher among the CRC patients than among the healthy individuals; however, this difference did not reach statistical significance. Moreover, as the authors compared healthy Japanese controls and Chinese CRC patients, the genetic backgrounds of the populations may have been different. Based on the finding of the $h M L H 1$ V384D variant in $2.5 \%$ of the healthy Japanese controls, the authors concluded that this variant is a polymorphism confined to the East-Asian population rather than a cancer-susceptibility variant. However, they did not analyze phenotype-genotype segregation, clinicopathological features or total MMR activity by, for example, performing a yeast-based functional assay or an in vitro MMR assay. Therefore, the possibility of a cancer-causing variant of V384D remains.

On the other hand, a GTT to GAT nucleotide substitution at codon 384 replaces the neutral hydrophobic amino-acid valine with aspartic acid, an acidic amino-acid with a negative charge, indicating a change in the structure of the protein. However, codon 384 is located in a poorly conserved region outside the regions of $h M L H 1$, with well-defined functions, ATPase activity at the $\mathrm{NH}_{2}$ terminus and the ability to bind hPMS2 at the COOH terminus (24-26).

Fan et al examined the MMR activity of the V384D variant based on its interaction with PMS2, and demonstrated a partial loss of its MMR activity, thereby suggesting an increased risk of gastrointestinal cancer in V384D carriers (16).

Takahashi et al evaluated MMR activity by means of three yeast assays (LacZ, GFP and ADE2) and an in vitro MMR assay with mismatched heteroduplex DNA, and succeeded in developing a functional database for $101 \mathrm{hMLHl}$ variants (15). The MMR activity of the V384D variant in their study was found to be $64.8 \%$, determined to be within normal levels, as MMR activity of $60 \%$ or higher is defined as a normal.

These authors also estimated the MMR activity of the $h M L H 1415 \mathrm{C} / \mathrm{D} 132 \mathrm{H}$ variant, which was recently associated with an approximately 5-fold increase in CRC susceptibility among Israelis, to be $63 \%$ (25). The allele frequency of the $415 \mathrm{C}$ variant was reported to be $1.3 \%$ among Israelis, and clinicopathological analysis revealed that the average age of CRC onset in $415 \mathrm{C}$ carriers was 70.1 years, with no gender difference. Among the $h M L H 1415 \mathrm{C}$ patients, $28.6 \%$ were found to have a first-degree relative with Lynch syndrome-related tumors. Only one carrier developed a second primary tumor, while none had metachronous CRC. Based on the above findings, in contrast to Lynch syndrome, $h M L H 1415 \mathrm{C}$ carriers do not have a clear familial history, but do have an increased risk of sporadic CRC without MSI.

In the present study, similar results regarding the $h M L H 1$ $415 \mathrm{C} / \mathrm{D} 132 \mathrm{H}$ variant in V384D carriers were found; namely, no clear differences were apparent between V384D carriers and non-carriers in terms of clinicopathological features, such as age at diagnosis, gender, tumor site, histology, family history 
Table II. Frequency of the V384D variant.

\begin{tabular}{lrrr}
\hline Codon 384 & CRC patients, $\mathrm{n}=670(\%)$ & Control, $\mathrm{n}=332(\%)$ & $\mathrm{p}$-value \\
\hline V/V & $630(94.0)$ & $327(98.5)$ & \\
V/D & $39(5.8)$ & $5(1.5)$ & $<0.002$ \\
D/D & $1(0.2)$ & $0(0.0)$ &
\end{tabular}

$\mathrm{V}$, valine; D, aspartic acid

Table III. Clinical features of the CRC patients with or without V384D variant.

\begin{tabular}{|c|c|c|c|}
\hline & Non-V384D, no. (\%) & V384D, no. (\%) & p-value \\
\hline Patients & $630(94.0)$ & $40(6.0)$ & \\
\hline \multicolumn{4}{|l|}{ Gender } \\
\hline Male & $364(57.8)$ & $27(67.5)$ & \multirow[t]{2}{*}{0.13} \\
\hline Female & $266(42.2)$ & $13(32.5)$ & \\
\hline Age (mean $\pm \mathrm{SD}$, years $)$ & $63.4 \pm 13.4$ & $61.1 \pm 10.9$ & 0.08 \\
\hline Size of tumor (mean $\pm \mathrm{SD}, \mathrm{mm})$ & $46.9 \pm 17.5$ & $43.9 \pm 10.4$ & 0.09 \\
\hline \multicolumn{4}{|l|}{ Site of tumor } \\
\hline Cecum & $41 \quad(6.5)$ & $2(5.0)$ & \multirow{6}{*}{0.24} \\
\hline Ascending colon & $84(13.3)$ & $2(5.0)$ & \\
\hline Transverse colon & $56 \quad(8.9)$ & $4(10.0)$ & \\
\hline Descending colon & $20 \quad(3.2)$ & $4(10.0)$ & \\
\hline Sigmoid colon & $165(26.2)$ & $11(27.5)$ & \\
\hline Rectum & $264(41.9)$ & $17(42.5)$ & \\
\hline \multicolumn{4}{|l|}{ Histological grade } \\
\hline Well differentiated & 74 (11.7) & $5(12.5)$ & \multirow{3}{*}{0.19} \\
\hline Moderately differentiated & $514(81.6)$ & $34(85.0)$ & \\
\hline Poorly differentiated & $42 \quad(6.7)$ & $1 \quad(2.5)$ & \\
\hline Mucinous component $(+)$ & $81(12.9)$ & $0 \quad(0.0)$ & \\
\hline \multicolumn{4}{|l|}{ Dukes' stage } \\
\hline A & $139(22.1)$ & $8(20.0)$ & \multirow{4}{*}{0.09} \\
\hline $\mathrm{B}$ & $181(28.7)$ & $16(40.0)$ & \\
\hline $\mathrm{C}$ & $181(28.7)$ & $12(30.0)$ & \\
\hline $\mathrm{D}$ & $129(20.5)$ & $4(10.0)$ & \\
\hline Multiple CRC & $41 \quad(6.6)$ & $3(7.5)$ & 0.33 \\
\hline Extracolonic cancers & $71(11.3)$ & $4(10.0)$ & 0.26 \\
\hline \multicolumn{4}{|l|}{ MSI } \\
\hline MSI-H & $38 \quad(6.0)$ & $2(5.0)$ & \multirow{3}{*}{$0.14^{\mathrm{a}}$} \\
\hline MSI-L & $37 \quad(5.9)$ & $4(10.0)$ & \\
\hline MSS & $555(88.1)$ & $34(85.0)$ & \\
\hline
\end{tabular}

${ }^{a}$ MSI-H and MSI-L vs. MSS

of cancer or MSI status, but the frequency of the V384D allele was 4.1-fold higher in the CRC patients than in the healthy controls. According to Dukes' stage, an increase in Dukes' B $(40.5 \%)$ and decrease in Dukes' D (10.8\%) were observed in the CRC group with the V384D variant. This proportion of tumor stage is very similar to that seen in MSI-H tumors $(8,23)$.
The single CRC patient who was homozygous for V384D developed synchronous adenocarcinoma of the transverse colon and a rectal carcinoid at 64 years of age, and had a 6-year prior history of gastric cancer, but no familial history of cancer. The colon cancer in this case was not MSI-H. Certain clinical features of this patient, such as proximal colon cancer and 
multiple cancers, resembled the clinical features of Lynch syndrome.

Concerning MSI status, only $5.0 \%$ of the CRC patients with $h M L H 1$ V384D were MSI-H. Thus, the clinical and molecular features of the $h M L H 1$ V384D variant are very similar to those of the D132H variant (26). Certain patients with the $h M L H 1$ variant may exhibit partially impaired MMR activity without MSI; thus, the $h M L H 1$ variant may be associated with increased CRC susceptibility without early onset or clear familial history of CRC.

The $h M L H 1$ V384D variant seems to directly affect tumor susceptibility; however, the possibility that the V384D variant is linked to other surrounding pathogenic mutations must be considered. Further investigation is needed to clarify these issues.

\section{Acknowledgements}

This work was supported in part by a Grant-in-Aid from the Japanese Ministry of Health, Labor and Welfare.

\section{References}

1. Lynch HT and de la Chapelle A: Hereditary colorectal cancer. N Engl J Med 348: 919-932, 2003.

2. Leach FS, Nicolaides NC, Papadopoulos N, Liu B, Jen J, Parsons R, Peltomaki P, Sistonen P, Aaltonen LA, Nystrom-Lahti M, Guan XY, Zhang J, Meltzer PS, Yu JW, Kao FT, Chen DJ, Cerosaletti KM, Keith-Fournier RE, Todd S, Lewis T, Leach RJ, Naylor SL, Weissenbach J, Mecklin JP, Jarvinen H, Petersen GM, Hamilton SR, Green J, Jass J, Watson P, Lynch HT, Trent JM, de la Chapelle A, Kinzler KW and Vogelstein B: Mutations of a mutS homolog in hereditary non-polyposis colorectal cancer. Cell 75: 1215-1225, 1993.

3. Bronner CE, Baker SM, Morrison PT, Warren G, Smith LG, Lescoe MK, Kane M, Earabino C, Lipford J, Lindblom A, Tannergard P, Bollag RJ, Godwin AR, Ward DC, Fishel R, Kolodner $\mathrm{R}$ and Liskay M: Mutation in the DNA mismatch repair gene homologue $h M L H 1$ is associated with hereditary nonpolyposis colon cancer. Nature 368: 258-261, 1994.

4. Papadopoulos N, Nicolaides NC, Wei YF, et al: Mutation of a mutL homolog in hereditary colon cancer. Science 263: 1625-1629, 1994.

5. Papadopoulos N, Nicolaides NC, Liu B, et al: Mutations of GTBP in genetically unstable cells. Science 268: 1915-1917, 1995.

6. Peltomaki $\mathrm{P}$ and Vasen H: Mutations associated with HNPCC predisposition-update of ICG-HNPCC/INSIGHT mutations data base. Dis Markers 20: 269-276, 2004.

7. Hampel H, Frankel WL, Martin E, Arnold M, Khanduja K, Kuebler P, Nakagawa H, Sotamaa K, Prior TW, Westman J, Panescu J, Fix D, Lockman J, Comeras I and de la Chapelle A: Screening for the Lynch syndrome (hereditary non-polyposis colorectal cancer). N Engl J Med 352: 1851-1860, 2005.

8. Ishikubo T, Nishimura Y, Yamaguchi K, Khansuwan U, Arai Y, Kobayashi T, Ohkura Y, Hashiguchi Y, Tanaka Y and Akagi K: The clinical features of rectal cancers with high-frequency microsatellite instability (MSI-H) in Japanese males. Cancer Lett 216: 55-62, 2004.

9. Pinol V, Castells A, Andreu M, Castellvi-Bel S, Alenda C, Llor X, Xicola RM, Rodriguez-Moranra F, Paya A, Jover R and Bessa X: Accuracy of revised Bethesda guidelines, microsatellite instability and immunohistochemistry for the identification of patients with hereditary non-polyposis colorectal cancer. Jama 293: 1986-1994, 2005.

10. Ward R, Meagher A, Tomlinson I, O'Connor T, Norrie M, Wu R and Hawkins N: Microsatellite instability and the clinicopathological features of sporadic colorectal cancer. Gut 48: 821-829, 2001.
11. Herman JG, Umer A, Polyak K, Graff JR, Ahuja N, Issa JP, Markowitz S, Willson JK, Hamilton SR, Kinzler KW, Kane MF, Kolodner RD, Vogelstein B, Kunkel TA and Baylin SB: Incidence and functional consequences of $h M L H 1$ promoter hyper-methylation in colorectal carcinoma. Proc Natl Acad Sci USA 95: 6870-6875, 1998.

12. Cunningham JM, Christensen ER, Tester DJ, Kim CY, Roche PC, Burgart LJ and Thibodeau SN: Hypermethylation of the $h M L H I$ promotor in colon cancer with microsatellite instability. Cancer Res 58: 3455-3460, 1998.

13. Vasen HF, Watson P, Mecklin JP and Lynch HT: New clinical criteria for hereditary non-polyposis colorectal cancer (HNPCC, Lynch syndrome) proposed by the International Collaborative group on HNPCC. Gastroenterol 116: 1453-1456, 1999.

14. Umer A, Boland CR, Terdiman JP, Syngal S, de la Chapelle A, Ruschoff J, Fishel R, Lindor NM, Burgart LJ, Hamelin R, Hamilton SR, Hiatt RA, Jass J, Lindblom A, Lynch HT, Peltomaki P, Ramsey SD, Rodriquez-Bigas MA, Vasen HF, Hawk ET, Barrett JC, Freedman AN and Srivastava S: Revised Bethesda guidelines for hereditary non-polyposis colorectal cancer (Lynch syndrome) and microsatellite instability. J Natl Cancer Inst 96: 261-268, 2004.

15. Takahashi M, Shimodaira H, Andreutti-Zaugg C, Iggo R, Kolodner RD and Ishioka C: Functional analysis of human MLHI variants using yeast and in vitro mismatch repair assays. Cancer Res 67: 4595-4604, 2007.

16. Fan Y, Wang W, Zhu M, Zhou J, Peng J, Xu L, Hua Z, Gao X and Wang Y: Analysis of $h M L H 1$ missense mutations in East Asian patients with suspected hereditary non-polyposis colorectal cancer. Clin Cancer Res 13: 7515-7521, 2007.

17. Lee SC, Guo JY, Lim R, Soo R, Koay E, Salto-Tellez M, Leong A and Goh BC: Clinical and molecular characteristics of hereditary non-polyposis colorectal cancer families in Southeast Asia. Clin Genet 68: 137-145, 2005.

18. Wang Y, Friedl W, Lamberti C, Nothen MM, Kruse R and Propping P: A novel missense mutation in the DNA mismatch repair gene $h M L H 1$ present among East Asians but not among Europeans. Hum Hered 48: 87-91, 1998.

19. Wang Y, Zhou J, Li Z, Gao C and Gao P: One of the etiological factors of digestive tract cancers in Chinese: the missense mutations Val384Asp in the $h M L H 1$ gene. Zhonghua Yi Xue Yi Chuan Xue Za Zhi 17: 82-86, 2000.

20. Akagi K, Uchibori R, Yamaguchi K, Kurosawa K, Tanaka Y and Kozu T: Characterization of a novel oncogenic K-ras mutation in colon cancer. Biochem Biophys Res Commun 352: 728-732, 2007.

21. Boland CR, Thibodeau SN, Hamilton SR, Sidransky D, Eshleman JR, Burt RW, Meltzer SJ, Rodrinquez-Bigas MA, Fodde R, Ranzani GN and Srivastava S: A National Cancer Institute workshop on microsatellite instability for cancer detection and familial predisposition: development of international criteria for the determination of microsatellite instability in colorectal cancer. Cancer Res 58: 5248-5257, 1998.

22. Kotake K, Honjo S, Sugihara K, Kato T, Kodaira S, Takahashi T, Yasutomi M, Muto T and Koyama Y: Changes in colorectal cancer during a 20-year period: an extended report from the multi-institutional registry of large bowel cancer, Japan. Dis Colon Rectum 46: S32-S43, 2003.

23. Asaka S, Arai Y, Nishimura $Y$, Yamaguchi $K$, Ishikubo $T$, Yatsuoka T, Tanaka Y and Akagi K: Microsatellite instability-low colorectal cancer acquiers a K-ras mutation during the progression from Dukes' A to Dukes' B. Carcinogenesis 30: 494-499, 2009.

24. De la Chapelle A: Genetic predisposition to colorectal cancer. Nat Rev Cancer 4: 769-780, 2004.

25. Moslein G, Tester DJ, Lindor NM, Honchel R, Cunningham JM, French AJ, Halling KC, Schwab M, Goretzki P and Thibodeau SN: Microsatellite instability and mutation analysis of $h M S H 2$ and $h M L H 1$ in patients with sporadic, familial and hereditary colorectal cancer. Hum Mol Genet 5: 1245-1252, 1996.

26. Lipkin SM, Rozek LS, Rennert G, Yang W, Chen PC, Hacia J, Hunt N, Shin B, Fodor S, Kokoris M, Greenson JK, Fearon E, Lynch H, Collins F and Gruber SB: The $M L H 1$ D132H variant is associated with susceptibility to sporadic colorectal cancer. Nat Genet 36: 694-699, 2004. 